\title{
Impact of B-type natriuretic peptide level on the risk of left atrial appendage thrombus in patients with nonvalvular atrial fibrillation: a prospective study
}

Rojina Pant ${ }^{1}$, Mita Patel ${ }^{2,3}$, Enrique Garcia-Sayan ${ }^{2,4}$, Marwan Wassouf ${ }^{2,5}$, Oliver D'Silva', Richard F. Kehoe and Rami Doukky ${ }^{2,6^{*}}$

\begin{abstract}
Background: The impact of B-type natriuretic peptide (BNP) level on the risk of left atrial appendage (LAA) thrombus in patients with nonvalvular atrial fibrillation (NVAF) has not been prospectively studied.

Methods: In two academic medical centers, we obtained BNP levels immediately prior to transesophageal echocardiogram performed to exclude LAA thrombus in patients with NVAF.

Results: Among 261 subjects (mean age $65 \pm 12$ years; $30 \%$ women) with NVAF, 17 (6.5\%) had LAA thrombus and 85 (32.6 \%) had at least mild spontaneous echo contrast (SEC). Mean BNP level was significantly higher in patients with LAA thrombus [775 \pm 678 vs. $384 \pm 537, P=0.001]$. Receiver operator characteristics analysis demonstrated that BNP has a good discriminatory capacity for LAA thrombus (area under the curve, 0.74; $95 \%$ confidence interval [Cl], $0.63-0.85 ; P=0.001) ; B N P \geq 67 \mathrm{pg} / \mathrm{mL}$ was $100 \%$ sensitive and $20 \%$ specific for LAA thrombus. Multivariate logistic regression analysis demonstrated that BNP was not independently associated with LAA thrombus (odds-ratio, 1.05 per $100 \mathrm{pg} / \mathrm{mL}$ increment; $\mathrm{Cl}, 0.99-1.12 ; P=0.127)$ after adjusting for $\mathrm{CHA}_{2} \mathrm{DS}_{2}-$ VASc score; while the latter was independently associated with LAA thrombus after adjusting for BNP level (odds-ratio, 1.46 per $\mathrm{CHA}_{2} \mathrm{DS}_{2}$-VASC point; $C l, 1.09-1.96 ; P=0.011)$. Nonetheless, BNP was associated with SEC in univariate and multivariate analysis, after adjusting for the $\mathrm{CHA}_{2} \mathrm{DS}_{2}$-VASC score, (odds-ratio, 1.08; $\mathrm{Cl}, 1.02-1.14 ; P=0.005$ ).
\end{abstract}

Conclusions: BNP is predictive of SEC. However, it does not provide significant incremental value in the prediction of LAA thrombus.

Keywords: Atrial fibrillation, B-type natriuretic peptide, Left atrial appendage thrombus, Spontaneous echo contrast

\section{Background}

Systemic thromboembolism is a serious complication in patients with nonvalvular atrial fibrillation (NVAF) [1]. Over the past several years, various types of scoring systems, such as the $\mathrm{CHADS}_{2}$ and $\mathrm{CHA}_{2} \mathrm{DS}_{2}$-VASc scores have been developed for predicting the risk of embolic events in NVAF patients $[2,3]$. These clinical risk scores seem to offer a modest discriminatory value for the

\footnotetext{
* Correspondence: rdoukky@cookcountyhhs.org

${ }^{2}$ Division of Cardiology, Rush University Medical Center, Chicago, IL, USA

${ }^{6}$ Division of Adult Cardiology, John H. Stroger, Jr. Hospital of Cook County, 1901 W. Harrison St, Chicago, IL 60612, USA

Full list of author information is available at the end of the article
}

individual patients [2]. Biomarkers of myocardial stress such as B-type natriuretic peptide (BNP) have a large body of evidence showing association with clinical events and may help refine risk assessment in NVAF patients [4]. Atrial dysfunction is an established risk factor for thrombus formation in NVAF patients and BNP has been shown to originate from dysfunctional and stressed atrial myocadium in these patients [5-7]. Moreover, elevated left ventricular filling pressure leads to left atrial blood stasis and thrombus formation, which respectively manifest on transesophageal echocardiography (TEE) as spontaneous echo contrast (SEC) and left atrial appendage (LAA) thrombus [8-10]. Thus, BNP, a surrogate for left 
ventricular filling pressure, may help identify patients at risk for left atrial blood stasis and LAA thrombus [11, 12]. Indeed, in retrospective non-concomitant assessment of BNP levels and LAA thrombus by TEE, our group has demonstrated an association between plasma BNP level and the formation of SEC and LAA thrombi in patients with NVAF, independent of clinical covariates [13]. The present study aims to prospectively and concomitantly investigate the predictive value of BNP level in identifying LAA thrombus and SEC formation in patients with NVAF.

\section{Methods}

\section{Patient population and study design}

We prospectively enrolled consecutive adult patients with NVAF who were referred to undergo TEE to "rule-out" LAA thrombus at the echocardiography laboratories of Rush University Medical Center (Chicago, IL) and Advocate Illinois Masonic Medical Center (Chicago, IL) in the period between January 7, 2011 and November 14, 2013. Eligible patients underwent plasma BNP level measurement from a blood sample drawn immediately before the reference TEE.

Patients with valvular atrial fibrillation were excluded; those were patients with mitral stenosis, mitral regurgitation greater than $2+$ in severity (scale, $0-4)$, or any mitral valve surgical or percutaneous intervention. Additionally, patients with complex congenital heart disease and orthotopic heart transplantation were excluded. Patients with isolated aortic valvular disease, aortic valve prosthesis, and right-sided valvular heart disease were not excluded. All subjects signed an informed and HIPAA consent prior to enrollement. The study was funded by an internal research grant and approved by the institutional review board of each participating institution.

\section{Clinical data}

Data including patient demographics, comorbidities, anticoagulation status, and antiplatelet use were prospectively collected prior to the TEE. Atrial fibrillation chronicity was classified as: 1) paroxysmal, defined as spontaneously reverting to sinus rhythm within 7 days; 2) persistent, defined as lasting more than 7 days but less than 12 months, or any atrial fibrillation events terminated by electrical or chemical cardioversion or radiofrequency ablation within 12 months of onset; or 3) permanent, defined as events lasting more than 12 months [14]. The $\mathrm{CHADS}_{2}$ score was calculated from the sum of risk predictors of congestive heart failure, hypertension, age $\geq 75$ years, diabetes mellitus, stroke or transient ischemic attack; weighing each risk predictor by "1" except for prior stroke/transient ischemic attack which was weighed by "2" [2]. The $\mathrm{CHA}_{2} \mathrm{DS}_{2}$-VASc score was calculated from the sum of the risk factors of congestive heart failure, hypertension, age $65-74$ or $\geq 75$ years, diabetes mellitus, stroke/transient ischemic attack, vascular disease, female gender; weighing each by "1" except for stroke/transient ischemic attack and age $\geq 75$ years which were weighed by " 2 " $[3,15]$. Congestive heart failure was defined as a history of clinical heart failure or left ventricular ejection fraction (LVEF) $<40 \%$. Vascular disease was defined as peripheral arterial disease, complex aortic plaque, or prior myocardial infarction [3]. The left ventricular end-systolic and enddiastolic volumes and LVEF were prospectively determined using the biplane Simpson's method [16] from a transthoracic echocardiogram acquired immediately prior to the reference TEE [16]. The LA volume was measured using single-plane Simpson's method in the apical 4 chamber view [16]. The left ventricular mass was calculated using the Devereux formula [17]. All volume and mass measurements were indexed to the body surface area.

\section{B-type natriuretic peptide}

A blood sample for BNP level was drawn immediately prior to induction of sedation for the reference TEE. Blood samples were processed at the respective inpatient laboratory of the participating institutions. BNP level was expressed in $\mathrm{pg} / \mathrm{mL}$.

\section{Transesophageal echocardiography}

TEE studies were performed under moderate or deep sedation, as clinically appropriate. An expert National Board of Echocardiography certified echocardiographer, who was blinded to BNP and clinical data, reviewed all TEE images to determine the presence or absence of LAA thrombus, defined as a circumscribed and uniformly echo-dense intracavitary mass distinct from the underlying left atrial or LAA endocardium and the pectinate muscles, and present in more than one imaging plane (Fig. 1a) [18]. LAA sludge, defined as a dynamic gelatinous, precipitous echodensity, without a discrete mass, present throughout the cardiac cycle, was categorized as LAA thrombus $[19,20]$. SEC was defined as dynamic "smoke-like" echoes with the characteristic swirling motion with optimal gain setting during the entire cardiac cycle (Fig. 1b) and was classified from 1 to 4 based on the criteria described by Fatkin et al [21]. Peak LAA emptying velocity at the LAA orifice was measured using pulsed wave Doppler and averaged over $3-5$ beats.

\section{Outcomes}

The primary outcome of the study was TEE-identified LAA thrombus. The secondary outcome was TEEidentified SEC.

\section{Statistical analysis}

The two-tailed Student's $t$-test was used to compare normally distributed continuous variables, which were expressed as mean \pm standard deviation. The Mann-Whitney test was 

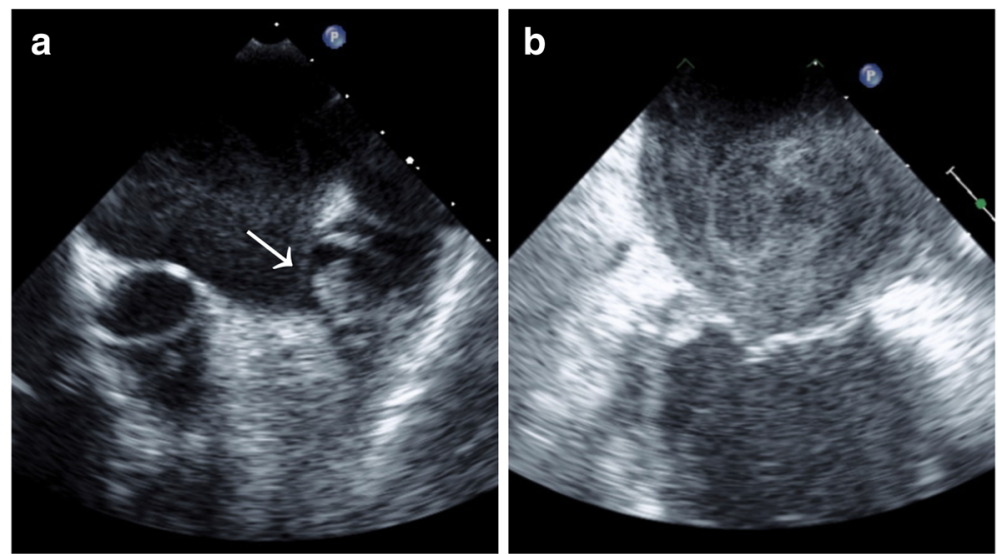

Fig. 1 Representative Examples. a, left atrial appendage thrombus (arrow); b, left atrial spontaneous echo contrast. Reproduced from Doukky et al. [29], with permission

used to compare skewed data. The chi-square test was used to compare categorical variables, which were expressed as frequencies and percentages. The Spearman's method was used to evaluate linear correlations.

The receiver operating characteristic (ROC) methodology was used to analyze the discriminatory capacity of $\mathrm{BNP}$ and $\mathrm{CHA}_{2} \mathrm{DS}_{2}$-VASc score in predicting LAA thrombus. ROC analyses were expressed as curve plots and calculated area under the curve (AUC) with $95 \%$ confidence intervals $(\mathrm{CI})$ and associated $P$ value representing the likelihood of the null hypothesis $(\mathrm{AUC}=0.5$ ).

The association between BNP level (in $100 \mathrm{pg} / \mathrm{mL}$ increments) as main independent variable, and LAA thrombus or SEC (outcome variable) was analyzed in univariate and multivariate binary logistic regression models. In multivariate binary logistic regression models, we initially adjusted for the $\mathrm{CHA}_{2} \mathrm{DS}_{2}$-VASc score only, and in separate models we adjusted for the $\mathrm{CHA}_{2} \mathrm{DS}_{2}$-VASc score, LVEF, and oral anticoagulant use. Due to significant collinearity between BNP level and LA volume index (Spearman's $r=$ $0.41 ; P<0.001)$, LA volume index was not included in multivariate models. Risk was expressed as odds-ratios (OR) with CI. Goodness-of-fit for multivariate models was confirmed using Hosmer and Lemeshow test.

All tests were 2 -tailed, and a $P$ value $<0.05$ was considered statistically significant. PASW-22 software (IBM, Inc., Armonk, NY) was used for all data analyses.

\section{Results}

A total of 261 patients (mean age, $65 \pm 12$ years; $30 \%$ women) with NVAF were prospectively enrolled to undergo plasma BNP level measured in a blood sample drawn immediately prior to their clinically indicated TEE; 199 (76 \%) were recruited from Rush University Medical Center and 62 (24 \%) from Advocate Illinois Masonic Medical Center. The leading indications for TEE were "ruling-out" LAA thrombus prior to direct current cardioversion (39\%), catheter ablation (46\%), or implantation or testing of implantable cardioverter-defibrillator (10\%). At the time of the TEE, 34 (13\%) subjects were in sinus rhythm; the rest were in atrial dysrhythmia. Among the study subjects, 17 (6.5 \%) had a confirmed LAA thrombus by TEE. Table 1 compares the baseline characteristics of patients with and without LAA thrombus. Notably, patients with LAA thrombus had a significantly higher mean $\mathrm{CHA}_{2} \mathrm{DS}_{2}$-VASc and $\mathrm{CHADS}_{2}$ scores (both $P$ values $=0.001$ ), lower mean LVEF, larger LA volume index, lower mean LAA emptying velocity, higher prevalence of heart failure, and had a trend towards higher creatinine levels. Patients with LAA thrombus had statistically insignificant higher rates of Warfarin usage. Chronicity of NVAF was not different between patients with versus without LAA thrombus (Table 1).

\section{BNP and LAA Thrombus}

Subjects with LAA thrombus had a significantly higher mean BNP level than those without LAA thrombus [775 \pm 678 vs. $384 \pm 537, P=0.001$ ] (Table 1). Furthermore, there was a significant stepwise increase $(\mathrm{P}$ for trend $=$ 0.002) in the prevalence of LAA thrombus with increasing BNP level (Fig. 2). As shown in Fig. 3, ROC analysis demonstrated that BNP had a good discriminatory capacity for LAA thrombus (AUC, 0.74; CI, 0.63-0.85; $P=0.001$ ). BNP level $\geq 67 \mathrm{pg} / \mathrm{mL}$ was $100 \%$ sensitive and $20 \%$ specific for LAA thrombus, whereas BNP $\geq 100$ was $94 \%$ sensitive and $32 \%$ specific and $\mathrm{BNP} \geq 500$ was $53 \%$ sensitive and $78 \%$ specific for LAA thrombus. $\mathrm{CHA}_{2} \mathrm{DS}_{2}$-VASc score had similar discriminative capacity (AUC, 0.73; CI, 0.62-0.84; $P<0.001$ ); a score of $\geq 1$ was $100 \%$ sensitive for LAA thrombus (Fig. 3).

BNP was associated with LAA thrombus in univariate analysis (OR, 1.08 per $100 \mathrm{pg} / \mathrm{mL}$ increment; CI, $1.02-$ $1.15 ; P=0.010)$. However, in multivariate logistic regression 
Table 1 Baseline Characteristics

\begin{tabular}{|c|c|c|c|c|}
\hline & & LAA Throm & & \\
\hline & All Subjects & Present & Absent & $P$ value \\
\hline & $N=261$ & $N=17$ & $N=244$ & \\
\hline Age (years) & $65 \pm 12$ & $69 \pm 10$ & $65 \pm 12$ & 0.190 \\
\hline Age $\geq 75$ years & $56(21)$ & $5(29)$ & $51(21)$ & 0.409 \\
\hline Age $\geq 65$ years & $150(58)$ & $13(76)$ & $137(56)$ & 0.101 \\
\hline Female & $79(30)$ & $5(29)$ & $74(30)$ & 0.937 \\
\hline Hypertension & $196(75)$ & $15(88)$ & $181(74)$ & 0.195 \\
\hline Diabetes mellitus & $67(26)$ & $7(41)$ & $60(25)$ & 0.130 \\
\hline Congestive heart failure & $102(39)$ & $13(76)$ & $89(36)$ & 0.001 \\
\hline History of stroke or TIA & $35(13)$ & $5(29)$ & $30(12)$ & 0.045 \\
\hline Vascular disease & $53(20)$ & $5(29)$ & $48(20)$ & 0.334 \\
\hline Dyslipidemia & $126(48)$ & $9(53)$ & $117(48)$ & 0.691 \\
\hline BMI $\left(\mathrm{Kg} / \mathrm{m}^{2}\right)$ & $31.4 \pm 8.5$ & $28 \pm 5.7$ & $31.7 \pm 8.7$ & 0.091 \\
\hline Creatinine (mg/dL) & $1.3 \pm 1.1$ & $1.9 \pm 1.9$ & $1.2 \pm 1.0$ & $0.076^{*}$ \\
\hline Warfarin & $124(48)$ & $10(59)$ & $114(47)$ & 0.334 \\
\hline NOACs & $48(18)$ & $3(18)$ & $45(18)$ & 0.935 \\
\hline Antiplatelet & $140(54)$ & $9(53)$ & $131(54)$ & 0.952 \\
\hline $\mathrm{CHADS}_{2}$ score & $1.9 \pm 1.3$ & $2.9 \pm 1.3$ & $1.8 \pm 1.3$ & $0.001^{*}$ \\
\hline $\mathrm{CHA}_{2} \mathrm{DS}_{2}$-VASc Score & $3.0 \pm 1.8$ & $4.4 \pm 1.6$ & $3.0 \pm 1.8$ & $0.001^{*}$ \\
\hline AF chronicity & & & & 0.789 \\
\hline Paroxysmal & $67(26)$ & $5(29)$ & $62(25)$ & \\
\hline Persistent & $107(41)$ & $7(41)$ & $100(41)$ & \\
\hline Permanent & $34(13)$ & $3(18)$ & $31(13)$ & \\
\hline Unknown & $53(20)$ & $2(12)$ & $51(21)$ & \\
\hline LVEF (\%) & $47 \pm 17$ & $34 \pm 13$ & $48 \pm 17$ & 0.002 \\
\hline LVEDV index $\left(\mathrm{mL} / \mathrm{m}^{2}\right)$ & $54 \pm 29$ & $69 \pm 34$ & $53 \pm 29$ & 0.054 \\
\hline LV mass index $\left(\mathrm{g} / \mathrm{m}^{2}\right)$ & $103 \pm 41$ & $113 \pm 29$ & $102 \pm 41$ & 0.311 \\
\hline $\mathrm{LA}$ volume index $\left(\mathrm{mL} / \mathrm{m}^{2}\right)$ & $33 \pm 16$ & $42 \pm 18$ & $33 \pm 16$ & 0.035 \\
\hline Degree of SEC (scale 0-4) & $0.6 \pm 1.1$ & $3.0 \pm 1.1$ & $0.4 \pm 0.9$ & $<0.001^{*}$ \\
\hline SEC present & $85(33)$ & $17(100)$ & $68(28)$ & $<0.001$ \\
\hline LAA emptying velocity $(\mathrm{cm} / \mathrm{s})$ & $42 \pm 22$ & $25 \pm 11$ & $44 \pm 22$ & 0.001 \\
\hline BNP $(\mathrm{pg} / \mathrm{mL})$ & $409 \pm 554$ & $775 \pm 678$ & $384 \pm 537$ & $0.001^{*}$ \\
\hline
\end{tabular}

Data presented as mean \pm standard deviation or number (\%)

TA transient ischemic attack, $B M I$ body mass Index, NOACs novel oral anticoagulants, $A F$ atrial fibrillation, $L V E F$ Left ventricular ejection fraction, $L V E D V$ left ventricular end-diastolic volume, $L V$ left ventricular, $L A$ left atrial, SEC spontaneous echo contrast, $L A A$ left atrial appendage, $B N P B$-type natriuretic peptide, *Mann-Whitney test

analysis, adjusting for the $\mathrm{CHA}_{2} \mathrm{DS}_{2}$-VASc score, BNP was not independently associated with LAA thrombus (OR, 1.05 per $100 \mathrm{pg} / \mathrm{mL}$ increment; $\mathrm{CI}, 0.99-1.12 ; P=0.127)$, while the $\mathrm{CHA}_{2} \mathrm{DS}_{2}$-VASc score was independently associated with LAA thrombus after adjusting for BNP (OR, 1.46 per point; $\mathrm{CI}, 1.09-1.96 ; P=0.011)$. In the latter model, BNP level did not seem to provide significant incremental predictive value $\left(\Delta x^{2}=2.08, P=0.149\right)$ to the $\mathrm{CHA}_{2} \mathrm{DS}_{2}$ VASc score. In an expanded (over-fitted) multivariate logistic regression analysis model, adjusting for $\mathrm{CHA}_{2} \mathrm{DS}_{2}$-VASc score, LVEF, and oral anticoagulants use, BNP was not independently predictive of LAA thrombus (OR, 1.04 per $100 \mathrm{pg} / \mathrm{mL}$ increment; CI, 0.97-1.12; $P=0.229)$.

\section{BNP and spontaneous echo contrast}

Out of 261 study subjects, 85 (33\%) had at least mild SEC, including all 17 (100\%) individuals with LAA thrombus. The $\mathrm{CHA}_{2} \mathrm{DS}_{2}$-VASc score was associated with SEC (OR, 1.44 per 1 point increment; $C I, 1.23-1.68$; $P<$ $0.001)$. There were modest but highly significant correlations between the degree of SEC (scale, 0-4) and both the $\mathrm{CHA}_{2} \mathrm{DS}_{2}$-VASc score (Spearman $r=0.29, P<0.001$ ) and 


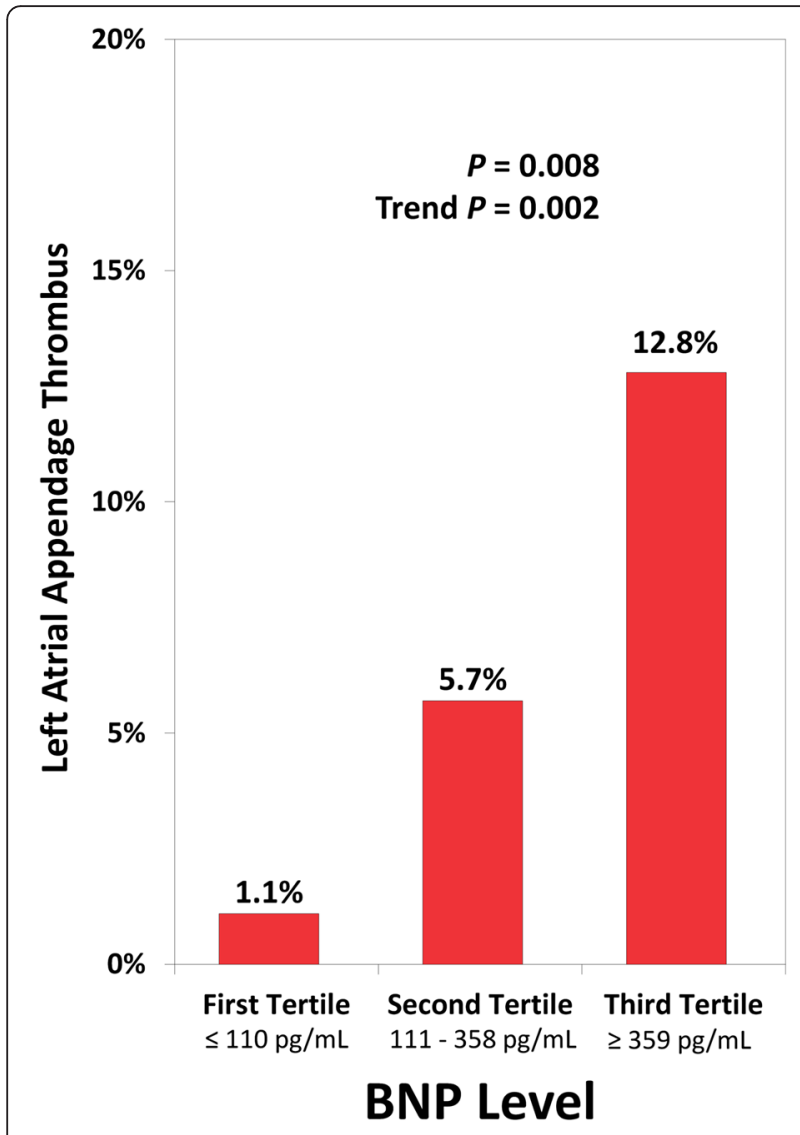

Fig. 2 Prevalence of Left Atrial Appendage Thrombus according to BNP level

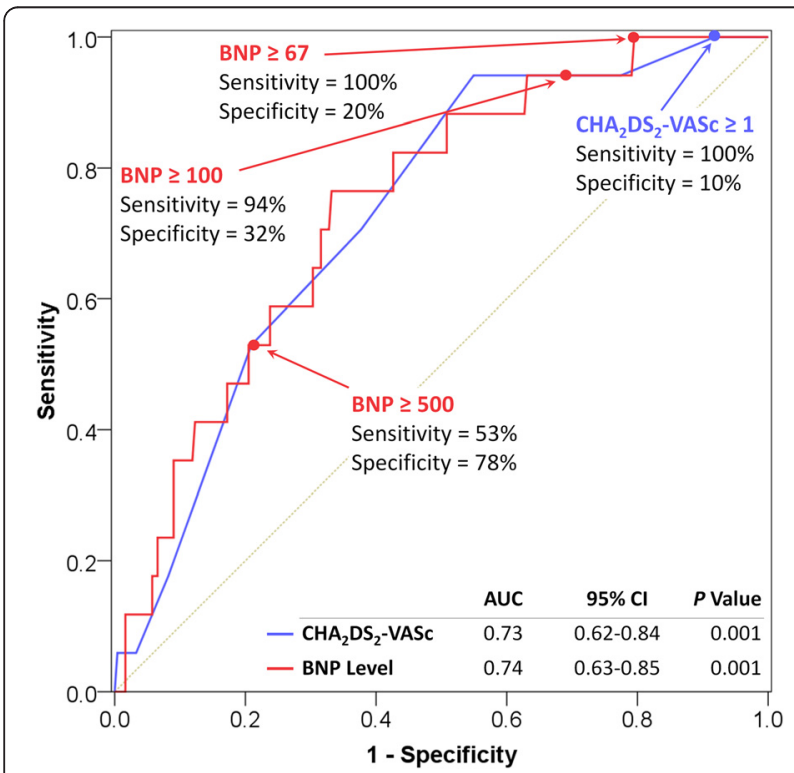

Fig. 3 Receiver Operating Characteristic Curves in Diagnosing LAA Thrombus. LAA, left atrial appendage; AUC, area under the curve; $\mathrm{Cl}$, confidence intervals
BNP (Spearman $r=0.32, P<0.001)$. In a multivariate logistic regression analysis model that included BNP level and the $\mathrm{CHA}_{2} \mathrm{DS}_{2}$-VASc score, BNP was independently predictive of SEC (OR, 1.08 per $100 \mathrm{pg} / \mathrm{mL}$ increment; CI, $1.02-1.14 ; P=0.005)$. In this model, the $\mathrm{CHA}_{2} \mathrm{DS}_{2}$-VASc score was also predictive of SEC (OR, 1.35; CI, 1.15-1.59; $P<0.001)$. In an expanded logistic regression model, that included BNP level, $\mathrm{CHA}_{2} \mathrm{DS}_{2}$-VASc score, $\mathrm{LVEF}$, and oral anticoagulant use, BNP was independently predictive of SEC (OR, 1.09; CI, 1.02-1.15; $P=0.007$ ).

\section{Discussion}

This is the first study to prospectively and concomitantly correlate the BNP level with LAA thrombus and SEC in patients with NVAF. This study showed that plasma BNP level was significantly higher in patients with LAA thrombus than in those without LAA thrombus. Despite small number of LAA thrombus events, we observed a stepwise relationship between BNP level (in tertiles) and risk of LAA thrombus. Thus, BNP level may help in identifying patients at risk for LAA thrombus. BNP level was independently predictive of SEC but not of LAA thrombus.

BNP is a neurohormone secreted from the myocytes mainly in response to increased wall tension such as volume or pressure overload and has been shown to be elevated in patients with NVAF [22]. Moreover, BNP has also been shown to predict future AF $[23,24]$ and risk of thromboembolism [13, 25]. Recent studies have shown BNP to be a valuable marker for general cardiovascular risk stratification in patients with NVAF [26]. Pathophysiologically, increased LV filling pressure causes atrial stretch, which is a well-known reason for development of NVAF [27]. Loss of effective atrial contraction during atrial fibrillation coupled with elevation in the left ventricular filling pressure can lead to left atrial blood stasis, manifesting as SEC, and subsequent risk for LAA thrombus [28, 29]. BNP level correlates with left ventricular filling pressure (6); thus, it may aid in predicting SEC and LAA thrombus. Indeed, in a retrospective analysis of 136 patients with NVAF our group demonstrated an association between BNP, a surrogate of LV filling pressure, and LAA thrombus and SEC [13]. The study demonstrated that BNP was predictive of LAA thrombus independent of the $\mathrm{CHADS}_{2}$ and $\mathrm{CHA}_{2} \mathrm{DS}_{2}$-VASc scores, which are known predictors of LAA thrombus and systemic embolization in NVAF. Additionally, the study showed that all patients with LAA thrombus had BNP level $>500 \mathrm{pg} / \mathrm{mL}$ [13]. Moreover, in another recent retrospective study of 524 non-anticoagulated NVAF patients, Ochiumi et al., [25] showed that BNP was an independent predictor of LAA thrombus, and identified plasma BNP level of $251 \mathrm{pg} / \mathrm{mL}$ as a useful cutoff for predicting LAA thrombus. Notably, both of the aforementioned studies were limited by 
retrospective design, incidental rather than systematic BNP level assessment with TEE, and non-concomitant BNP measurement with TEE.

The present investigation partially validates the finding of previous retrospective studies, [13, 25] as BNP was predictive of LAA thrombus only in univariate analysis but not in multivariate analysis after adjusting for the $\mathrm{CHA}_{2} \mathrm{DS}_{2}$-VASc score. However, BNP was predictive of SEC in univariate and multivariate analyses. Since SEC is a surrogate for LAA thrombus formation and thromboembolic events, [30] it is likely that lack of independent association between BNP and LAA thrombus is due to small sample size and limited number of events (type II error). Moreover, the present study demonstrated that LAA thrombus was present at much lower BNP level $(67 \mathrm{pg} / \mathrm{mL})$ than previously shown $[13,25]$. This significant difference in the BNP level associated with LAA thrombus is likely due to the fact that, given our prospective design, BNP levels were collected immediately prior to the TEE exam, when patients may have been near euvolemic state; whereas in other studies BNP was obtained when clinically indicated, at the height of patients' symptoms. Moreover, all patients in the present study had a BNP level measured. This was not the case in other published studies in which BNP levels were incidentally available among patients who underwent TEE studies, thus introducing a clear selection bias. Therefore, the current work is unique in several important aspects: 1 ) this is the only prospective study to investigate the impact of BNP on the risk of LAA thrombus; 2) the study was designed to include dual-center data; 3) concomitant BNP and TEE assessment; 4) we investigated consecutively enrolled patients to undergo BNP level measurement prior to TEE, which eliminates the bias introduced by analyzing patients who happen to have incidental BNP measurement.

The association between BNP and SEC suggests that elevated left ventricular filling pressure is associated with left atrial blood stasis manifesting as SEC. This association was independent of other factors such as LVEF, and oral anticoagulants. This finding also support the findings regarding LAA thrombus since SEC is the precursor for LAA thrombus formation.

It was notable that 13 patients were found to have LAA thrombus despite oral anticoagulant use. This observation likely reflects the recognition of elevated thromboembolic risk by the treating physician. It also indicates that oral anticoagulants are not fully protective of LAA thrombus among high risk NVAF patients.

The present investigation has two important clinical implications: 1) BNP level can be used as a useful predictor for LAA thrombus and SEC; 2) Patients with very low BNP levels seem to be at low risk for LAA thrombus and perhaps systemic embolic events.
The study is limited by a relatively small sample size and infrequent LAA thrombus events, which impaired our ability to analyze many covariates within a given multivariate logistic regression model. However, the secondary SEC analyses were consistent with the primary endpoint analyses; thus adding validity to the study conclusions.

\section{Conclusions}

In patients with NVAF, BNP is predictive of SEC independent of clinical risk factors encompassed in the $\mathrm{CHA}_{2} \mathrm{DS}_{2}$-VASc score. BNP level can help predicting LAA thrombus in patients with NVAF, but does not seem to provide significant incremental predictive value beyond the $\mathrm{CHA}_{2} \mathrm{DS}_{2}$-VASc score.

\section{Abbreviations}

AUC: area under the curve; BNP: B-type natriuretic peptide; Cl: 95 \% confidence intervals; LAA: left atrial appendage; LVEF: left ventricular ejection fraction; NVAF: nonvalvular atrial fibrillation; OR: odds-ratio; ROC: receiver operating characteristic; SEC: spontaneous echo contrast.

\section{Competing interests}

The authors declare that they have no competing interests.

\section{Authors' contributions}

RP: recruitment, image interpretation, manuscript drafting. MP: recruitment, image interpretation, manuscript editing. EGS: recruitment, image interpretation, manuscript editing. MW: recruitment, data managment. OD: recruitment, image interpretation. RFK: site principal inverstigator. RD: principal investigator, concept, design, data analysis, data interpretation, critical revisions, final manuscript approval.

\section{Acknowledgments}

The study was funded by a Rush-County collaborative research grant. The grant fiduciary was Rush University Medical Center; the principal investigator was Dr. Doukky. The funding source had no input into the study design, execution, data analysis and interpretation, or manuscript preparation and approval.

\section{Disclosures}

Dr. Doukky receives research funding from Astellas Pharma US and serves on the Advisory Board of Astellas Pharma US. The other authors report no conflicts.

\section{Author details}

${ }^{1}$ Division of Cardiology, Advocate Illinois Masonic Medical Center, Chicago, IL, USA. Division of Cardiology, Rush University Medical Center, Chicago, IL, USA. ${ }^{3}$ Division of Cardiology, Medical College of Wisconsin, Milwaukee, WI, USA. ${ }^{4}$ Division of Cardiology, Mount Sinai Hospital, Chicago, IL, USA.

${ }^{5}$ Department of Medicine, Fairview Hospital, Cleveland, OH, USA. ${ }^{6}$ Division of Adult Cardiology, John H. Stroger, Jr. Hospital of Cook County, 1901 W.

Harrison St, Chicago, IL 60612, USA.

Received: 27 December 2015 Accepted: 12 January 2016

Published online: 16 January 2016

\section{References}

1. Benjamin EJ, Wolf PA, D'Agostino RB, Silbershatz H, Kannel WB, Levy D. Impact of atrial fibrillation on the risk of death: the Framingham Heart Study. Circulation. 1998:98(10):946-52

2. Gage BF, Waterman AD, Shannon W, Boechler M, Rich MW, Radford MJ. Validation of clinical classification schemes for predicting stroke: results from the National Registry of Atrial Fibrillation. JAMA. 2001;285(22):2864-70.

3. Lip GY, Nieuwlaat R, Pisters R, Lane DA, Crijns HJ. Refining clinical risk stratification for predicting stroke and thromboembolism in atrial fibrillation using a novel risk factor-based approach: the euro heart survey on atrial fibrillation. Chest. 2010;137(2):263-72. 
4. Wang TJ, Larson MG, Levy D, Benjamin EJ, Leip EP, Omland T, et al. Plasma natriuretic peptide levels and the risk of cardiovascular events and death. $\mathrm{N}$ Engl J Med. 2004;350(7):655-63.

5. Goetze JP, Friis-Hansen L, Rehfeld JF, Nilsson B, Svendsen JH. Atrial secretion of B-type natriuretic peptide. Eur Heart J. 2006;27(14):1648-50.

6. Inoue $S$, Murakami $Y$, Sano K, Katoh H, Shimada T. Atrium as a source of brain natriuretic polypeptide in patients with atrial fibrillation. J Card Fail. 2000;6(2):92-6.

7. Yasue H, Yoshimura M, Sumida H, Kikuta K, Kugiyama K, Jougasaki M, et al. Localization and mechanism of secretion of B-type natriuretic peptide in comparison with those of A-type natriuretic peptide in normal subjects and patients with heart failure. Circulation. 1994;90(1):195-203.

8. Bernhardt P, Schmidt H, Hammerstingl C, Luderitz B, Omran H. Patients at high risk with atrial fibrillation: a prospective and serial follow-up during 12 months with transesophageal echocardiography and cerebral magnetic resonance imaging. J Am Soc Echocardiogr. 2005;18(9):919-24.

9. Leung DY, Black IW, Cranney GB, Hopkins AP, Walsh WF. Prognostic implications of left atrial spontaneous echo contrast in nonvalvular atrial fibrillation. J Am Coll Cardiol. 1994;24(3):755-62.

10. Zabalgoitia M, Halperin JL, Pearce LA, Blackshear JL, Asinger RW, Hart RG. Transesophageal echocardiographic correlates of clinical risk of thromboembolism in nonvalvular atrial fibrillation. Stroke Prevention in Atrial Fibrillation III Investigators. J Am Coll Cardiol. 1998;31(7):1622-6.

11. Lubien E, DeMaria A, Krishnaswamy P, Clopton P, Koon J, Kazanegra R, et al. Utility of B-natriuretic peptide in detecting diastolic dysfunction: comparison with Doppler velocity recordings. Circulation. 2002;105(5):595-601.

12. Bakowski D, Wozakowska-Kaplon B, Opolski G. The influence of left ventricle diastolic function on natriuretic peptides levels in patients with atrial fibrillation. Pacing Clin Electrophysiol. 2009;32(6):745-52.

13. Doukky R, Gage H, Nagarajan V, Demopoulos A, Cena M, Garcia-Sayan E, et al. B-type natriuretic Peptide predicts left atrial appendage thrombus in patients with nonvalvular atrial fibrillation. Echocardiography. 2013;30(8):889-95.

14. January CT, Wann LS, Alpert JS, Calkins H, Cigarroa JE, Cleveland Jr JC, et al. 2014 AHA/ACC/HRS guideline for the management of patients with atrial fibrillation: a report of the American College of Cardiology/American Heart Association Task Force on Practice Guidelines and the Heart Rhythm Society. J Am Coll Cardiol. 2014;64(21):e1-76

15. Camm AJ, Kirchhof P, Lip GY, Schotten U, Savelieva I, Ernst S, et al. Guidelines for the management of atrial fibrillation: the Task Force for the Management of Atrial Fibrillation of the European Society of Cardiology (ESC). Eur Heart J. 2010;31(19):2369-429.

16. Lang RM, Badano LP, Mor-Avi V, Afilalo J, Armstrong A, Ernande L, et al. Recommendations for cardiac chamber quantification by echocardiography in adults: an update from the American Society of Echocardiography and the European Association of Cardiovascular Imaging. J Am Soc Echocardiogr. 2015;28(1):1-39. e14.

17. Devereux RB, Alonso DR, Lutas EM, Gottlieb GJ, Campo E, Sachs I, et al. Echocardiographic assessment of left ventricular hypertrophy: comparison to necropsy findings. Am J Cardiol. 1986:57(6):450-8.

18. Aschenberg W, Schluter M, Kremer P, Schroder E, Siglow V, Bleifeld W. Transesophageal two-dimensional echocardiography for the detection of left atrial appendage thrombus. J Am Coll Cardiol. 1986;7(1):163-6.

19. Puwanant S, Varr BC, Shrestha K, Hussain SK, Tang WH, Gabriel RS, et al. Role of the CHADS2 score in the evaluation of thromboembolic risk in patients with atrial fibrillation undergoing transesophageal echocardiography before pulmonary vein isolation. J Am Coll Cardiol. 2009;54(22):2032-9.

20. Wazni OM, Tsao HM, Chen SA, Chuang HH, Saliba W, Natale A, et al: Cardiovascular imaging in the management of atrial fibrillation. J Am Coll Cardiol. 2006;48(10):2077-84.

21. Fatkin D, Herbert E, Feneley MP. Hematologic correlates of spontaneous echo contrast in patients with atrial fibrillation and implications for thromboembolic risk. Am J Cardiol. 1994;73(9):672-6.

22. Wozakowska-Kaplon B. Effect of sinus rhythm restoration on plasma brain natriuretic peptide in patients with atrial fibrillation. Am J Cardiol. 2004;93(12):1555-8.

23. Schnabel RB, Larson MG, Yamamoto JF, Sullivan LM, Pencina MJ, Meigs JB, et al. Relations of biomarkers of distinct pathophysiological pathways and atrial fibrillation incidence in the community. Circulation. 2010;121(2):200-7.

24. Patton KK, Ellinor PT, Heckbert SR, Christenson RH, DeFilippi C, Gottdiener JS, et al. N-terminal pro-B-type natriuretic peptide is a major predictor of the development of atrial fibrillation: the Cardiovascular Health Study. Circulation. 2009:120(18):1768-74.

25. Ochiumi Y, Kagawa E, Kato M, Sasaki S, Nakano Y, Itakura K, et al. Usefulness of brain natriuretic peptide for predicting left atrial appendage thrombus in patients with unanticoagulated nonvalvular persistent atrial fibrillation. J Arrhythm. 2015;31(5):307-12.

26. Nakamura M, Koeda Y, Tanaka F, Onoda T, Itai K, Ohsawa M, et al. Plasma B-type natriuretic peptide as a predictor of cardiovascular events in subjects with atrial fibrillation: a community-based study. PLoS One. 2013;8(12):e81243.

27. Solti F, Vecsey $T$, Kekesi $V$, Juhasz-Nagy A. The effect of atrial dilatation on the genesis of atrial arrhythmias. Cardiovasc Res. 1989;23(10):882-6.

28. Doukky R, Khandelwal A, Garcia-Sayan E, Gage H. External validation of a novel transthoracic echocardiographic tool in predicting left atrial appendage thrombus formation in patients with nonvalvular atrial fibrillation. Eur Heart J Cardiovas Imaging. 2013;14(9):876-81.

29. Doukky R, Garcia-Sayan E, Gage H, Nagarajan V, Demopoulos A, Cena M, et al. The value of diastolic function parameters in the prediction of left atrial appendage thrombus in patients with nonvalvular atrial fibrillation. Cardiovasc Ultrasound. 2014;12(1):10.

30. Vincelj J, Sokol I, Jaksic O. Prevalence and clinical significance of left atrial spontaneous echo contrast detected by transesophageal echocardiography. Echocardiography. 2002;19(4):319-24.

\section{Submit your next manuscript to BioMed Central and we will help you at every step:}

- We accept pre-submission inquiries

- Our selector tool helps you to find the most relevant journal

- We provide round the clock customer support

- Convenient online submission

- Thorough peer review

- Inclusion in PubMed and all major indexing services

- Maximum visibility for your research

Submit your manuscript at www.biomedcentral.com/submit
) Biomed Central 